\title{
DESENVOLVIMENTO DE UM SISTEMA AUTOMATIZADO PARA O MONITORAMENTO DO EFEITO DA CHUVA NA ESTABILIDADE DE TALUDES INFINITOS
}

DOI: $10.37702 / 2175-957 X . C O B E N G E .2021 .3585$

Amanda Luzia Santos Silveira - amanda_luzia@hotmail.com

CEFET MG

Rua Luiz Leite 375

38184-286 - Araxá - MG

Larissa Caroline Silva - larissa_289@outlook.com

CEFET MG

Rua João Batista Fernandes 441

38184-112 - Araxá - MG

Kleber Lopes Fontoura - kleberfontoura@gmail.com

Centro Federal de Educação Tecnológica de Minad Getais

Alameda do Sol 320

38181-415 - Araxá - MG

Allan Erlikhman Medeiros Santos - allanerlikhman@cefetmg.br

CENTRO FEDERAL DE EDUCAÇÃO TECNOLÓGICA DE MINAS GERAIS

PRAÇADOUTOR BENEDITO GONÇALVES XAVIER 51

35400-000 - OURO PRETO - MG

Maicon Fernando Dias Torres - maicon170689@gmail.com

Centro Federal de Educação Tecnológica

Isolina Neves 125

38180-636 - Araxá - MG

Gustavo Oliveira Martins - gustavo_martins90@hotmail.com

Mosaic Fertilizantes

Argeu Alves da Costa 800

38138-372 - Araxá - MG

Resumo: Os taludes infinitos são estruturas em rocha ou solo que possuem 
grande extensão e espessura, sendo utilizados em diversas áreas, principalmente nas Engenharias de Minas e Civil. A ruptura de tais estruturas pode causar danos diretos e indiretos, em muitas situações irreversíveis. A percolação de águas pluviais em taludes é um dos principais gatilhos em problemas de instabilidade, ocasionando a saturação desses materiais e, consequentemente, reduzindo suas forças resistivas até um ponto crítico, no qual acontece o seu rompimento. $A$ presente pesquisa tem como principal objetivo a proposição de um sistema para o monitoramento do efeito das chuvas na estabilidade de taludes infinitos. $O$ projeto consiste na medição automatizada do volume de precipitação em um talude por meio de um pluviômetro digital. Os dados captados são transmitidos via wireless por um transceptor e, à determinada distância, em um escritório por exemplo, recebidos por outro transceptor. Após receber os dados, um software desenvolvido em linguagem " $C$ sharp" calcula o fator de segurança em tempo real. O programa desenvolvido é capaz de relacionar o volume de água obtido com o fator de segurança com base nas análises determinísticas para estabilidade de taludes. As variáveis relacionadas são: ângulo de atrito, inclinação do talude, coesão, altura do talude, porosidade, peso da amostra seca, peso específico da água e peso específico das partículas sólidas. O protótipo do sistema automatizado desenvolvido atendeu as expectativas, fornecendo em tempo real o fator de segurança do talude, para que, dessa forma, tragédias com danos materiais e fatais possam ser previstas e evitadas.

Palavras-chave: Estabilidade de Talude. Pluviosidade. Taludes infinitos. Software. 


\section{DESENVOLVIMENTO DE UM SISTEMA AUTOMATIZADO PARA O MONITORAMENTO DO EFEITO DA CHUVA NA ESTABILIDADE DE TALUDES INFINITOS}

\section{INTRODUÇÃO}

Os taludes infinitos são estruturas em rocha e/ou solo que possuem grande extensão e espessura, sendo comumente presente em encostas naturais e retaludadas em rodovias. Atualmente, uma das grandes dificuldades da geotecnia está relacionada a estabilidade de taludes. Tal fato ocorre devido aos impactos com caráter potencialmente catastróficos gerados por movimentação de massa que podem ser diretos e/ou indiretos resultando em problemas estruturais, econômicos e sociais.

As causas envolvendo rupturas de taludes podem estar associadas a diversos aspectos como geográficos, geológicos, geomorfológicos e climáticos. (CASTRO, 2012). A pluviosidade é um dos fatores de destaque em relação aos aspectos climáticos já que a mesma é capaz de gerar a mobilização quase imediata dos materiais que formam o talude, tanto pelo aumento rápido dos esforços como pela redução da resistência ao cisalhamento (HOYOS, 2014). No Brasil é comum ocorrer deslizamentos de massas em diversas regiões em períodos chuvosos fomentando em problemas sociais, ambientais e econômicos.

Uma maneira de evitar e controlar possíveis deslizamentos é por meio do monitoramento do talude em tempo real. Dessa forma, é exequível a execução de um plano de emergência para mitigar os danos e possibilitar a retirada da população que vive no entorno da encosta. O controle do talude pode ser realizado utilizando o fator de segurança que relaciona as forças atuantes e resistentes no maciço. Um método existente é $o$ de taludes infinitos, no qual, considera-se que o talude tem grandes extensões e uma espessura de solo capaz de se movimentar (GUERRA, 2015). Os valores limites admissíveis de fator de segurança irão depender das condições do talude e dos possíveis danos causados em uma condição de ruptura.

A pesquisa em questão teve como objetivo principal a proposta de um sistema de monitoramento para taludes infinitos. O monitoramento foi feito por meio de um programa desenvolvido que recebe os dados de volume de chuva infiltrado no solo e calcula o fator de segurança determinado com base nas análises determinísticas para estabilidade de taludes. As variáveis relacionadas são: ângulo de atrito, inclinação do talude, coesão, altura do talude, porosidade, peso da amostra seca, peso específico da água e peso específico das partículas sólidas. Por fim, um gráfico correlacionando 0 fator de segurança e tempo é plotado permitindo o monitoramento em tempo real.

\section{REFERENCIAL}

\subsection{Movimento de massas}

Os movimentos de massas configuram-se como eventos catastróficos e acontecem frequentemente em diversas localidades e com intensidades diferentes. Os mesmos apresentam um maior potencial em zonas tropicais e montanhosas visto que as características fisiológicas do relevo e das atividades antrópicas intensificam esses fenômenos (Schuster, 1996). Para Oliveira (2012), esses acontecimentos são de suma importância tanto em questão da evolução das encostas como em relação as consequências econômico-sociais resultantes dos processos de risco. 
As classificações dos movimentos de massas variam muito na bibliografia e uma delas se baseia em dois fatores: a velocidade de movimentação e a forma de ruptura. A partir disso, é possível agrupar em três grupos os movimentos de massas: escoamentos, subsidências e escorregamentos. O quadro abaixo mostra a classificação de massas por Freire (1965).

Quadro 1: Classificação dos movimentos de massas

\begin{tabular}{|c|c|c|c|c|}
\hline \multicolumn{2}{|c|}{ TIPO FUNDAMENTAL } & \multicolumn{2}{|c|}{ SUB-TIPO } & CLASSES PRINCIPAIS \\
\hline \multirow[t]{2}{*}{ 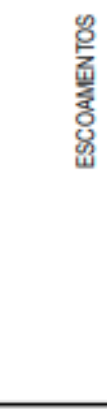 } & \multirow[t]{2}{*}{$\begin{array}{l}\text { CONSISTINDO EM } \\
\text { DEFORMA ÇAO OU } \\
\text { MOVIMENTO } \\
\text { CONTINUO COM OU } \\
\text { SEM SUPERFICIE } \\
\text { DEFINITINA DE } \\
\text { ESCORREGAMENTO }\end{array}$} & $\begin{array}{l}\text { RASTEJO } \\
\text { REPTAÇAOA }\end{array}$ & $\begin{array}{l}\text { Escoemento } \\
\text { Plástico }\end{array}$ & $\begin{array}{c}\text { 1,1,1-Rastejo de solo } \\
\text { 1.12-Rastejo de detritos. De } \\
\text { tálus } \\
\text { 1.1.3-Rastejo de rocha } \\
\text { 1.1.4- Solfluxáo } \\
\text { 1.1.5-Rastejo de detritos } \\
\text { 1.1.6-Geleiras }\end{array}$ \\
\hline & & CORRIDAS & $\begin{array}{l}\text { Escoamento } \\
\text { liquido }\end{array}$ & $\begin{array}{l}\text { 1.2.1- Corrida de terra } \\
\text { 1.2.- Corrida de areia ou } \\
\text { silte } \\
\text { 1.2.3- Corrida de Lama } \\
\text { 1.2.4-Avalanche de detritos }\end{array}$ \\
\hline \multirow[b]{2}{*}{ 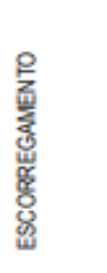 } & \multirow[b]{2}{*}{$\begin{array}{l}\text { CONSIST. EM } \\
\text { DESLOCAMENTO } \\
\text { FINITO AO LONGO DA } \\
\text { SUPERFICIE DE } \\
\text { MOVMENTO OU } \\
\text { DEFORMAÇAO }\end{array}$} & \multicolumn{2}{|c|}{$\begin{array}{l}\text { ESCORREGAMENTOS } \\
\text { ROTACIONAIS }\end{array}$} & \multirow[b]{2}{*}{$\begin{array}{l}\text { 2.1.1- Escorregamento de } \\
\text { Taludes } \\
\text { 2.1.2- Escorregamento de } \\
\text { base } \\
\text { 2.1.3- Rotura do solo ou } \\
\text { fundaçăo }\end{array}$} \\
\hline & & \multicolumn{2}{|c|}{$\begin{array}{l}\text { ESCORREGAMENTOS } \\
\text { TRANSLACIONAIS }\end{array}$} & \\
\hline \multirow[t]{3}{*}{ 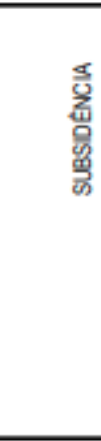 } & \multirow{3}{*}{$\begin{array}{c}\text { CONSISTE EM } \\
\text { DESLOCAMENTO } \\
\text { FINITO OU } \\
\text { DEFORMACCAOA } \\
\text { CONTINUA VERTICAL }\end{array}$} & \multicolumn{2}{|c|}{ SUBSIDENCIA } & \begin{tabular}{|l|} 
3.1.1- Carreamento de gräos \\
3.1.2-Dissoluçăa camadas \\
inferiores cavemas \\
3.1.3-Deformaçăo de \\
estratos inferiores \\
3.1.4- Rotura de estratos \\
infericres \\
3.1.5-Reirada do suporte \\
latreral \\
\end{tabular} \\
\hline & & \multicolumn{2}{|c|}{ RECALQUES } & $\begin{array}{l}\text { 3.2.1-Consolidaçăo } \\
\text { 3.2.2-Compactaçäo }\end{array}$ \\
\hline & & \multicolumn{2}{|c|}{ DESABAMENTOS } & $\begin{array}{c}\text { 3.3.1-Rohura de camada } \\
\text { 3.3.2-Subescavaçăo } \\
\text { 3.3.3-Refirada do suporte } \\
\text { lateral } \\
\end{array}$ \\
\hline 4 & & & & $\begin{array}{l}\text { Formas de transiçáo ou } \\
\text { termos de passagem }\end{array}$ \\
\hline 5 & & & & $\begin{array}{l}\text { Movimentos de massa } \\
\text { comolexos }\end{array}$ \\
\hline
\end{tabular}

Fonte: Freire (1965)

\subsection{Causas gerais de escorregamentos}

De acordo com Massad (2010) e Caputo (2003), as principais causas de movimentos de massa para estão relacionadas com o aumento de peso do talude e com as alterações de geometria do mesmo. No primeiro caso têm-se uma sobrecarga no topo das encostas enquanto no segundo ocorre $\mathrm{p}$ descalçamento do pé do talude por meio de cortes e escavações.

Segundo Oliveira (2012) e Massad (2010), a precipitação é uma condicionante importante em todos os tipos de movimentação de massas, principalmente, em escorregamentos e corridas. A infiltração de água eleva as pressões neutras reduzindo a resistência do solo que suscita na diminuição dos parâmetros de resistência, como 
exemplo a coesão aparente. Nesses casos, a umidade e/ou saturação do solo deflagam a desagregação e transporte do material.

No caso dos escorregamentos, a instabilidade do talude ocorre quando as tensões cisalhantes mobilizadas são iguais à resistência ao cisalhamento, ou seja, o fator de segurança do talude se torna 1.

\subsection{Análise de estabilidade}

De forma geral, a análise do fator de segurança possibilita averiguar o quanto uma encosta é e/ou será estável além de verificar movimentos já ocorridos. Existem duas abordagens possíveis: a análise probabilística e análise determinísticas A primeira é descrita como sendo o primeiro passo para a quantificação do risco geotécnico sendo necessário conhecer as distribuições ou funções de densidade de probabilidade e a estatística das variáveis inerentes ao problema. (CASTRO, 2012). Já a segunda está associada a obtenção de um fator de segurança e para tal é necessário obter valores fixos das variáveis de resistência ao cisalhamento (SOUZA E VIEIRA, 2007).

\subsection{Teoria de Equilíbrio Limite}

A análise por equilíbrio limite é baseada no equilíbrio de uma massa ativa ao longo de uma superfície com potencial de ruptura. Essa superfície pode apresentar diferentes geometrias, porém para as análises determina-se um mecanismo de ruptura para a superfície podendo ser circular, planar, etc. Além disso, os cálculos são realizados por meio das equações da estática tendo-se o equilíbrio de forças subdividindo a massa de solo em fatias para análise em cada uma. Nos métodos do equilíbrio limite nem sempre as três equações da estática são satisfeitas, portanto, cada método faz suas considerações para que seja possível realizar as análises.

\section{$2.5 \quad$ Talude Infinito}

$\mathrm{Na}$ teoria do equilíbrio limite existem diversos métodos possíveis de serem usados paras as análises de estabilidade. Cada um deles se propõe a verificar problemas diferentes sendo necessário, assim, seguir as premissas de cada método.

Um deles é o método de talude infinito que tem como premissa uma encosta natural com grandes extensões e uma espessura de solo fina capaz de se movimentar. A ruptura geralmente ocorre em contato com materiais de diferentes resistências com escorregamento translacional e paralelo a superfície (GUERRA, 2015). A figura 1 é um esquemático de um talude e seus elementos. 
Figura 1 - Elementos de um talude

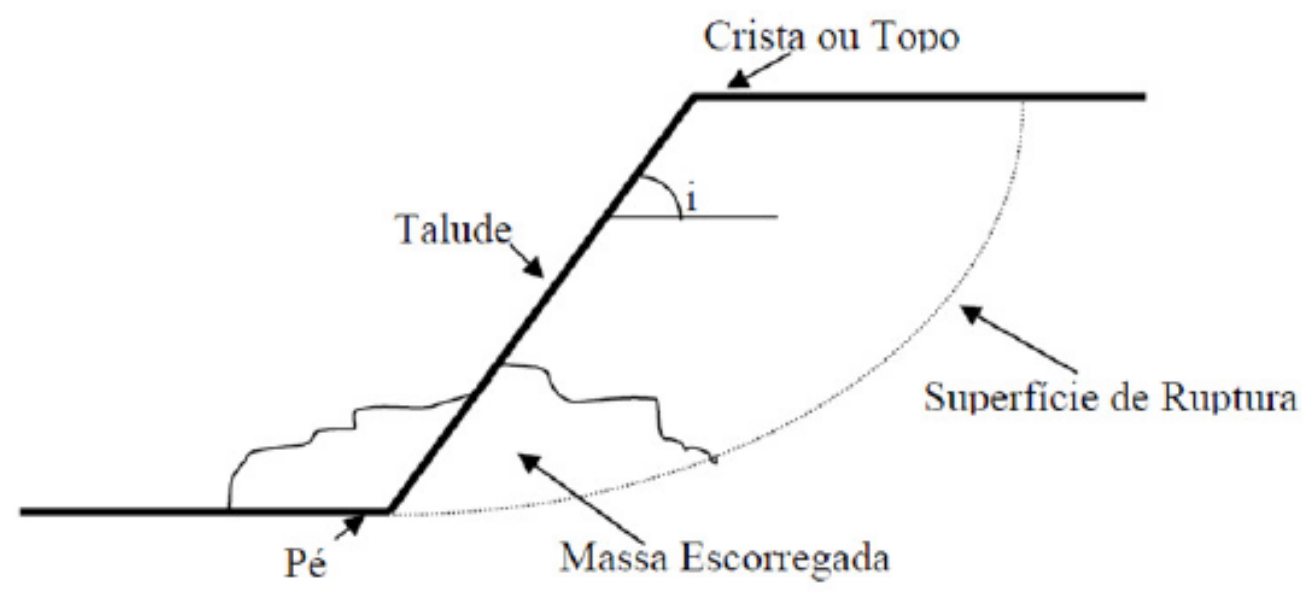

Fonte: Londe E Bitar (2011).

\section{METODOLOGIA}

Para a realização da pesquisa foram feitos levantamentos bibliográficos acerca de trabalhos publicados que envolvam as técnicas de monitoramento de taludes, a estabilidade de taludes infinitos e os sistemas de monitoramento existentes. A partir dos estudos realizados optou-se por utilizar a analise determinística com a teoria do equilíbrio limite sendo o método de talude infinito escolhido.

Para o desenvolvimento do programa de monitoramento, o primeiro passo consistiu na captação da pluviosidade por um pluviômetro digital que emite pulsos a cada 0,25 mm de chuva. Para coletar e enviar esses dados a um programa foi utilizado um módulo ESP 8266 que é um microcontrolador capaz de transmiti-los via wireless. Nesse caso, foi usado um receptor igual ao transmissor que se conecta a um cabo serial que por sua vez se conecta ao computador. Dessa forma, os dados obtidos são convertidos em serial antes de chegar ao computador permitindo que o programa faça a leitura.

O software para recebimento dos dados, cálculo do fator de segurança e monitoramento foi desenvolvido em uma plataforma livre tendo como linguem escolhida a "C SHARP". O programa é capaz de receber o dados e realizar o cálculos necessários, porém é necessário que algumas variáveis intrínsecas ao material (coesão, ângulo de atrito, porosidade, peso da amostra seca, peso específico da água, peso específico das partículas sólidas) e algumas características do próprio talude (altura e inclinação) sejam fornecidas pelo usuário. Com todos esses valores, o software calcula o fator de segurança baseado nas alterações que a percolação de água causa nos índices físicos do maciço.

O fator de segurança foi baseado em análises determinísticas para estabilidade de taludes e, para tanto, estudos acerca dos índices físicos foram realizados. A equação utilizada é descrita por Gerscovich (2009):

$$
F S=\frac{c^{\prime}+\left(\gamma \cdot h \cdot \cos ^{2} \beta-u\right) \cdot \tan \emptyset}{\gamma \cdot h \cdot \operatorname{sen} \beta \cdot \cos \beta}
$$

Com o valor de fator de segurança calculado o software plota um gráfico, fator de segurança $x$ tempo, que permite o monitoramento em tempo real do talude em análise. 
Além disso, foi usado um sistema fotovoltaico, já existente, que usa um painel solar para carregar duas baterias de lítio-íon alimentando o circuito de transmissão de dados.

\section{$4 \quad$ RESULTADOS}

Os dados obtidos na primeira etapa da pesquisa que consiste na captação da precipitação de chuva pelo pluviômetro foram satisfatórios. O pluviômetro é capaz de emitir pulsos a cada $0,25 \mathrm{~mm}$ enviando esses dados a cada $5 \mathrm{~mm}$ de chuva acumulados. O pluviômetro apresenta uma faixa de erro entre 3 a $7 \%$ sendo possível diminuir essa porcentagem com a aquisição de um pluviômetro mais preciso.

A transmissão dos dados coletados na etapa anterior foi condizente com 0 esperado sendo possível o envio via wireless por meio do módulo ESP 8266 que reconhece os pulsos gerados pelo pluviômetro. Para o recebimento dos dados foi utilizado o mesmo módulo de transmissão. Com um cabo específico foi feito a conversão dos dados recebidos pelo microcontrolador em serial possibilitando a leitura dos mesmos pelo computador e, consequentemente, pelo software.

Em relação ao software desenvolvido foi feito uma interface limpa e simplificada contendo três abas importantes sendo a de variáveis, porta serial e o gráfico de monitoramento. A figura 2 mostra essa página principal.

Figura 2 - Interface Inicial

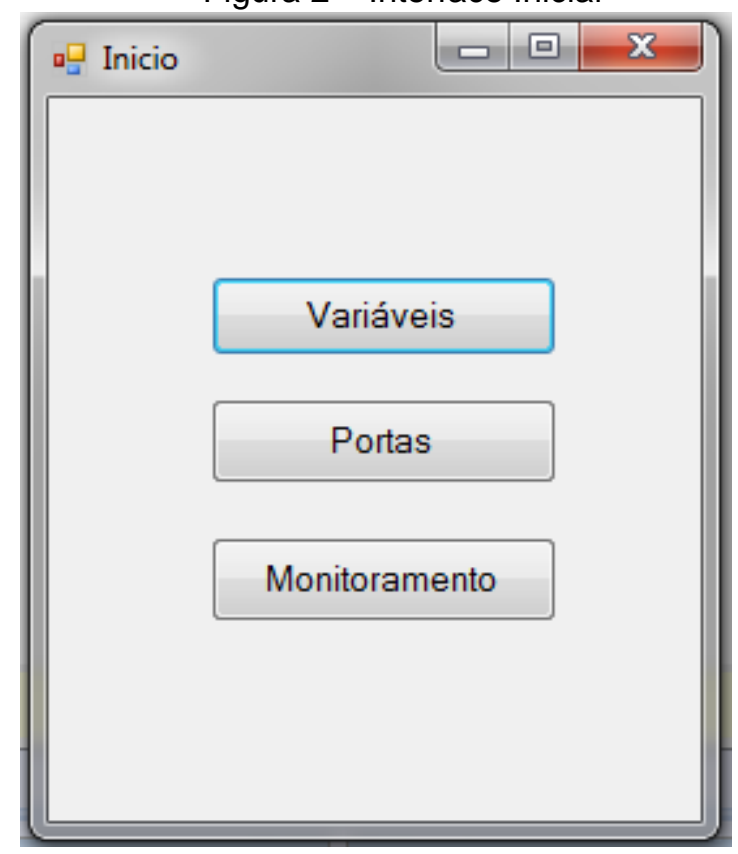

A aba denominada de variáveis foi destinada para que o usuário possa digitar todos os valores necessários para o cálculo. O calibrar representa a quantidade de água infiltrada no maciço permitindo que o usuário seja mais ou menos conservador variando entre 0 e 1 . Caso escolha o valor 1 , o mesmo está assumindo que todo o volume de chuva infiltrou no maciço. A figura 3 mostra essa interface. 
Figura 3 - Interface Variáveis

\begin{tabular}{|c|c|c|}
\hline Variaveis & & 8 \\
\hline Calibrar $(0-1)$ & 1 & \\
\hline Altura do Talude & 3 & \\
\hline Ängulo de Atrito & 20 & \\
\hline Coesão & 15 & \\
\hline Inclinação Talude & 60 & \\
\hline Porosidade & 0,595 & \\
\hline Peso dos Sólidos & 0,49 & \\
\hline Peso Part. Sólidas & 20 & \\
\hline & Salvar & \\
\hline
\end{tabular}

A segunda aba é referente as portas seriais, nela é possível verificar as portas disponíveis nas quais o software pode se comunicar. É por meio delas que o programa é capaz de receber os valores enviados pelo módulo ESP 8266 conectado ao computador. A figura 4 mostra como ficou essa seção.

Figura 4 - Interface Porta Serial

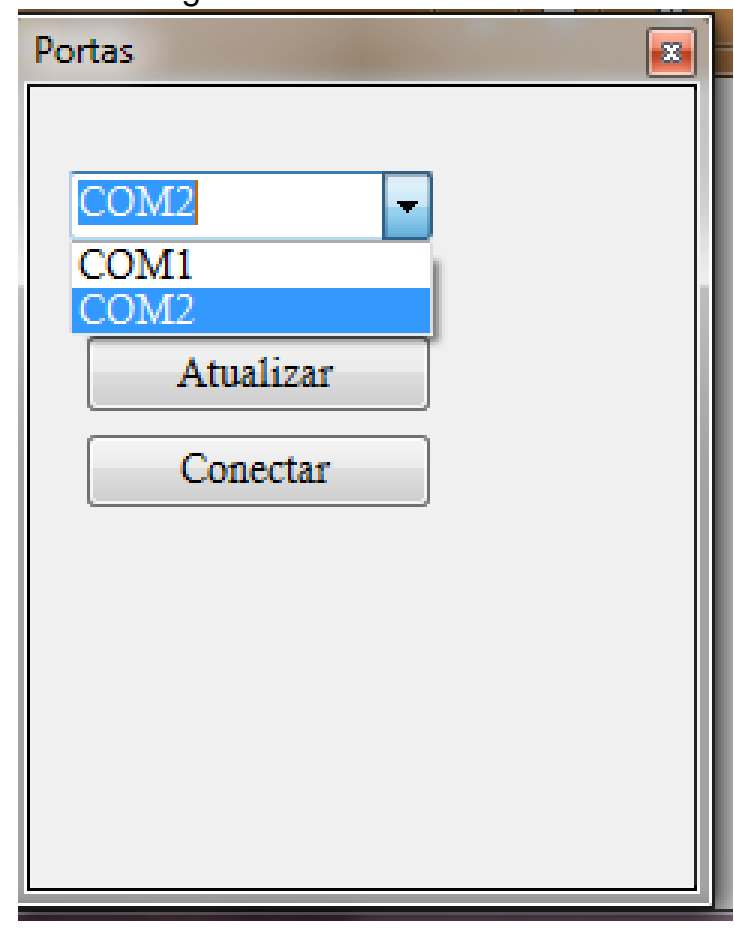

A última aba do programa é referente ao gráfico plotado para o monitoramento em tempo real. No eixo $x$ tem se o tempo em minutos e no eixo y o valor do fator de segurança calculado. $O$ gráfico permite seja feito o monitoramento acompanhando as 
variações do FS que quando menor que 1 o talude rompeu. A figura 5 mostra como ficou essa interface.

Figura 5 - Interface Monitoramento

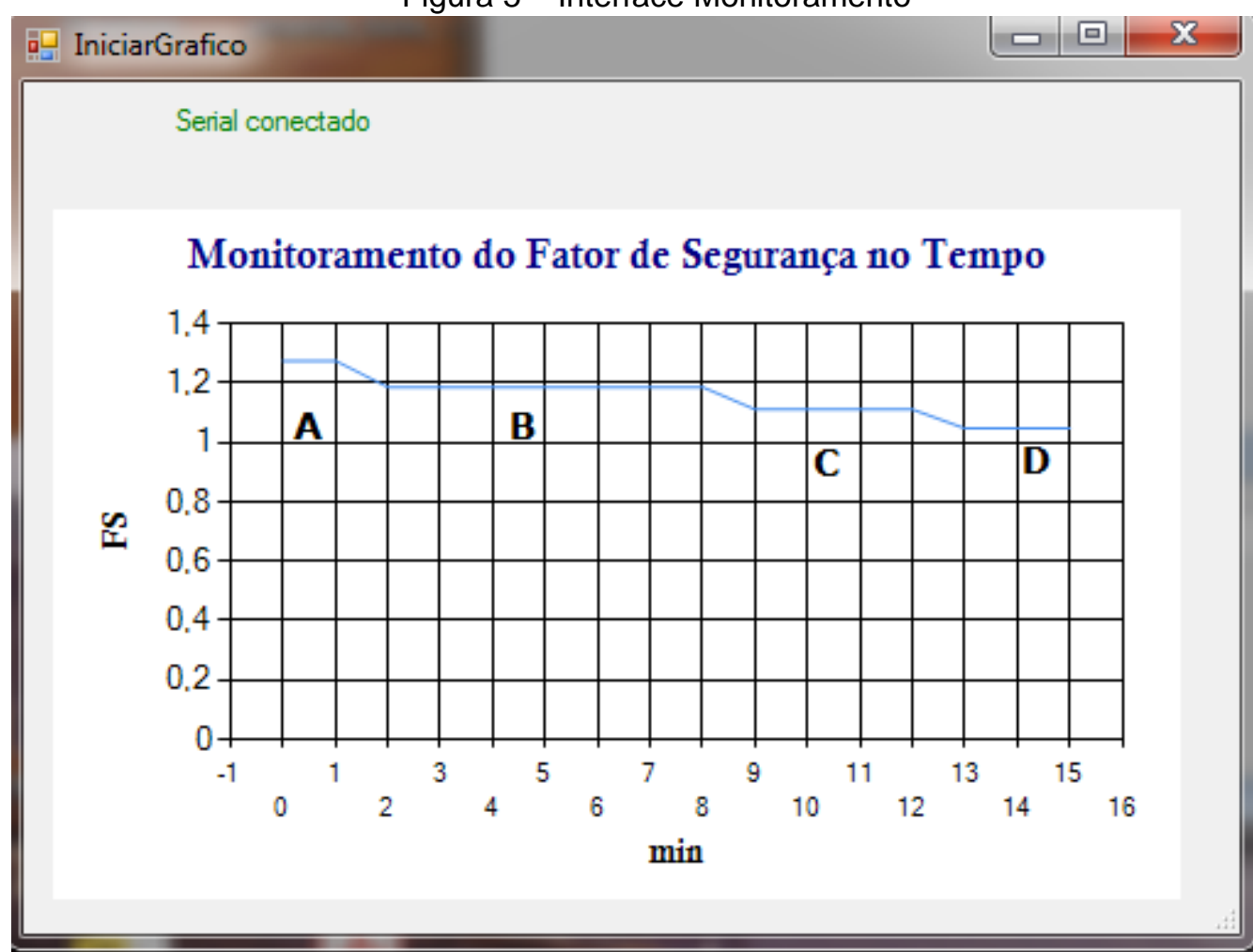

$\mathrm{Na}$ imagem acima, o gráfico mostra a variação do FS conforme o volume de chuva aumenta. No trecho A o volume de precipitação era de $5 \mathrm{~mm}$, no ponto $B$ de $10 \mathrm{~mm}$, no ponto $C$ de $15 \mathrm{~mm}$ e o no $D$ de $20 \mathrm{~mm}$.

A figura 6 mostra o gráfico anterior, porém com o ponto $E$ que representa $30 \mathrm{~mm}$ de chuva. Nesse caso simulado, o FS ficou abaixo de 1 por isso uma mensagem de alerta é exibida na tela informando que o talude rompeu. 
Figura 6 - Interface Monitoramento

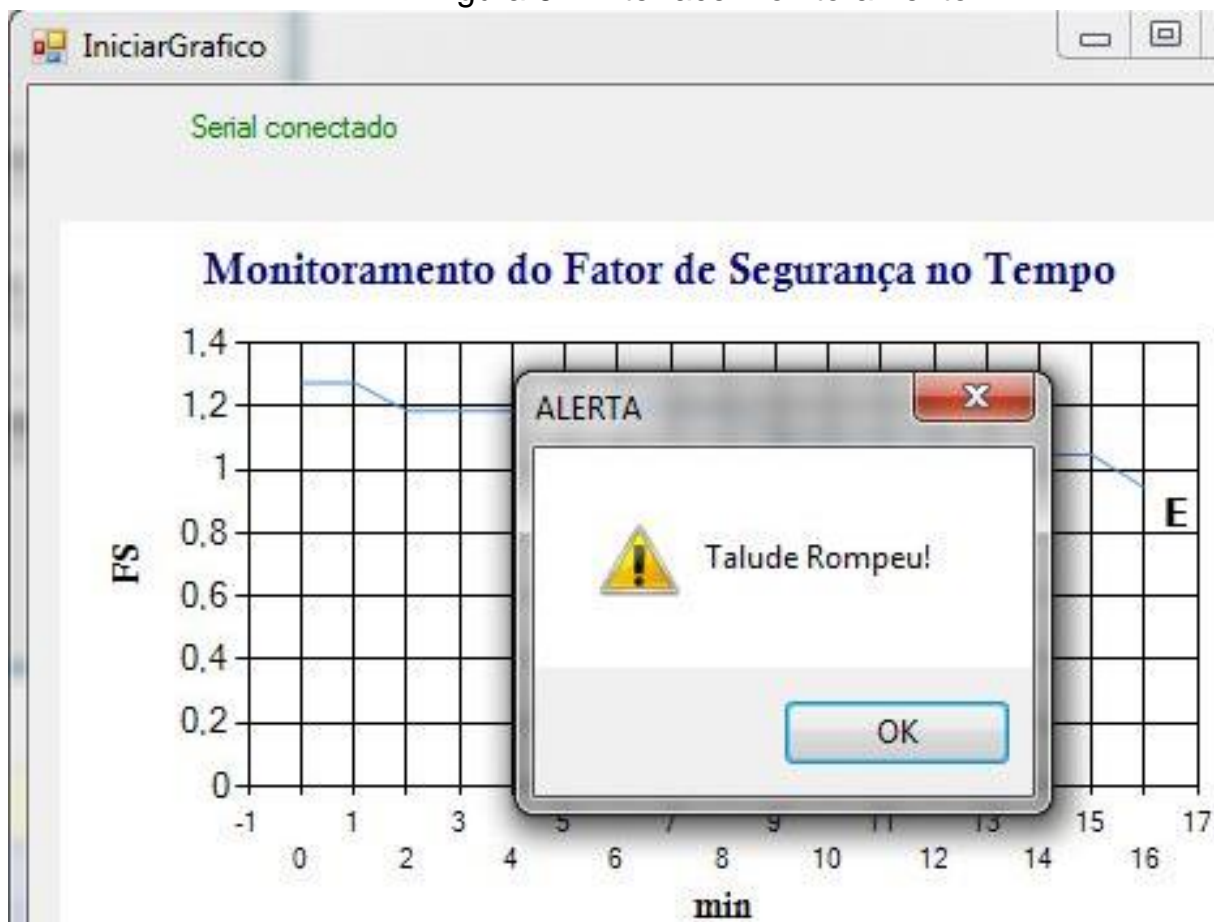

\section{CONSIDERAÇÕES FINAIS}

O monitoramento de taludes é extremamente importante para evitar possíveis catástrofes de cunho ambiental, social e econômico. A pesquisa em questão apresentou ótimos resultados atingindo seu objetivo principal de criar um sistema automatizado para monitoramento de taludes infinitos.

O objetivo do trabalho foi alcançado, o pluviômetro utilizado funcionou perfeitamente para a ideia proposta não sendo necessário nenhuma adaptação. 0 sistema de conexão via wireless conseguiu se comunicar com eficiência ao software desenvolvido. O programa por sua vez conseguiu entregar um sistema de monitoramento preciso e leve.

Com os resultados alcançados fica evidente a possibilidade de fazer monitoramentos de taludes de forma simples e econômica bem como a sua importância para a sociedade. Apesar de ser um método limitado por ter um único valor de fator de segurança representando toda a área o sistema pode ser utilizado para o controle e se necessário é possível fazer adaptações.

Sugere-se para novos trabalhos que sejam feitos estudos mais aprofundados da percolação de água em taludes infinitos analisando mapas hidro geológicos das regiões e outros métodos determinísticos afim de se aumentar a precisão e a confiabilidade do monitoramento.

\section{REFERÊNCIAS}

CAPUTO, H. P. Mecânica dos solos e suas aplicações. 6. ed. rev. Rio de Janeiro: LTC, 2003.

CASTRO, V. M. de. Estudo Sobre a Estabilidade da Encosta do Morro de Sapinhatuba I, Angra dos Reis, RJ. 2012. Trabalho de Conclusão de Curso - 
Universidade Federal do Rio de Janeiro, Rio de Janeiro, 2012. Disponível em: $<$ https://docplayer.com.br/70233498-Estudo-sobre-a-estabilidade-da-encosta-do-morrode-sapinhatuba-i-angra-dos-reis-rj.html>. Acesso em: 30 mar.2021.

CASTRO, V. M. de. Estudo Sobre a Estabilidade da Encosta do Morro de Sapinhatuba I, Angra dos Reis, RJ. 2012. Trabalho de Conclusão de Curso, Universidade Federal do Rio de Janeiro - Escola Politécnica, 2012. Disponível em: <https://docplayer.com.br/70233498Estudo-sobre-a-estabilidade-da-encosta-do-morro-de-sapinhatuba-i-angra-dos-reis-rj.html>. Acesso em: 30 mar. 2021.

FREIRE, E. S. M. Movimentos coletivos de solos e rochas e sua moderna sistemática. Revista Construção, Rio de Janeiro, p. 10-18, 1965.

GERSCOVICH, Denise. M. S. Estabilidade de Taludes. 2009. 160 f.- Notas de Aulas Faculdade de Engenharia da Universidade do Estado do Rio de Janeiro, Rio de Janeiro, 2009.

GUERRA, U. G. Retroanálise de Rupturas de Taludes em Nova Friburgo - RJ. 2015. Tese (Mestrado) - Programa de Engenharia Civil, Universidade Federal do Rio de Janeiro, Rio de Janeiro, 2015

Disponível em:

https://www.researchgate.net/publication/309223182_Retroanalise_de_rupturas_de_taludes_ em_Nova_Friburgo_RJ >. Acesso em: $20 \mathrm{fev} .2021$.

LONDE, P. R.; BITAR, N. A. Importância do uso de vegetação para contenção e combate à erosão em taludes do lixão desativado no município de Patos de Minas (MG). Perquirere: Patos de Minas: UNIPAM, 8(2):224-249, dez. 2011. Disponível em: <https://docplayer.com.br/11485217-Importancia-do-uso-de-vegetacao-para-contencao-ecombate-a-erosao-em-taludes-do-lixao-desativado-no-municipio-de-patos-de-minas-mg1.html>. Acesso em: 01 mar. 2021.

MASSAD, F. Obras de terra: curso básico de geotecnia. 2. ed. São Paulo: Oficina de Textos, 2010.

MUÑOZ-HOYOS, E. Influência dos Parâmetros Hidrológicos e Geotécnicos na Estabilidade de Taludes. 2014. Tese (Mestrado) - Universidade de Brasília, Brasília-DF, 2014. Disponível em: < https://www.researchgate.net/publication/266375429_Influencia_dos_Parametros_Hidrauli cos_e_Geotecnicos_na_Estabilidade_de_Taludes>. Acesso em: 19 mar.2021.

OLIVEIRA, G. A. Correlação entre Pluviometria, Piezometria e Movimentos das Encostas dos Quilômetros 87 e 101 da Rodovia BR 116/RJ (Rio-Teresópolis). Programa de Pósgraduação em Engenharia Civil (COPPE) da Universidade Federal do Rio de Janeiro. Rio de Janeiro. 2012.

SCHUSTER, R. L. Socioeconomic Significance Of Landslides. In: TURNER, A.K. \& SCHUSTER, R.L. (Eds.), Landslides: Investigation and Mitigation. Washington: National Academy Press, p. 12-35, 1996.

SOUZA, V. A. D.; VIEIRA, V. P. P. B. Análise probabilística da estabilidade do talude de jusante de uma barragem de terra em regime de operação. Comitê brasileiro de barragens. Xxvii seminário nacional de grandes barragens. Belém - pa, 03 a 07 de junho de 
2007. Disponível e: < https://docplayer.com.br/74657380-Analise-probabilistica-daestabilidade-do-talude-de-jusante-de-uma-barragem-de-terra-em-regime-de-operacao.html>. Acesso em: 10 mar. 2021.

\title{
INSTRUCTIONS FOR PREPARATION AND SUBMISSION OF WORKS TO THE SCIENTIFIC COMMITTEE OF XLIX BRAZILIAN CONGRESS OF ENGINEERING EDUCATION - COBENGE 2021
}

\begin{abstract}
The infinite slopes are structures in rock or soil that have great extension and thickness, being used in several areas, mainly in mining and civil engineering. The rupture of such materials can cause direct and indirect damage, in many irreversible situations. The percolation of rainwater on embankments is one of the main triggers in instability problems, causing the saturation of these materials, reducing their resistive forces to a critical point, at which they break. The main objective of this research is to monitor the effect of rain on the stability of infinite slopes. The project will initially consist of measuring the volume of precipitation on a slope using a digital rain gauge. The captured data will be transmitted wirelessly by a transceiver and, at a certain distance, in an office, for example, received by another transceiver. The information received will be stored in a database for the development of software that calculates the security factor in real time. The developed program must be able to relate the volume of water obtained with the safety factor by means of mathematical equations pre-established in the stability method to be studied. In the final part of this project, the prototype of an automated system for monitoring the safety factor of a slope is expected to function correctly, so that tragedies with material and fatal damage can be predicted and avoided. It is hoped that further research can be done in order to improve and adapt the prototype in several segments.
\end{abstract}

Keywords: Slope stability. Rainfall. Infinite slopes. Software. 